Xi-Shi Tai, Li-Hua Wang and Yu-Pei Xia*

\title{
The crystal structure of poly $\left[\mu_{2}\right.$-aqua- aqua- $\left(\mu_{3^{-}}\right.$ (E)-2-(4-((2-carbamothioylhydrazineylidene) methyl)phenoxy)acetato- $\left.\mathrm{K}^{3} \mathrm{O}: \mathrm{S}: \mathrm{S}\right)$ sodium(I)], $\mathrm{C}_{10} \mathrm{H}_{14} \mathrm{~N}_{3} \mathrm{O}_{5} \mathrm{SNa}$
}

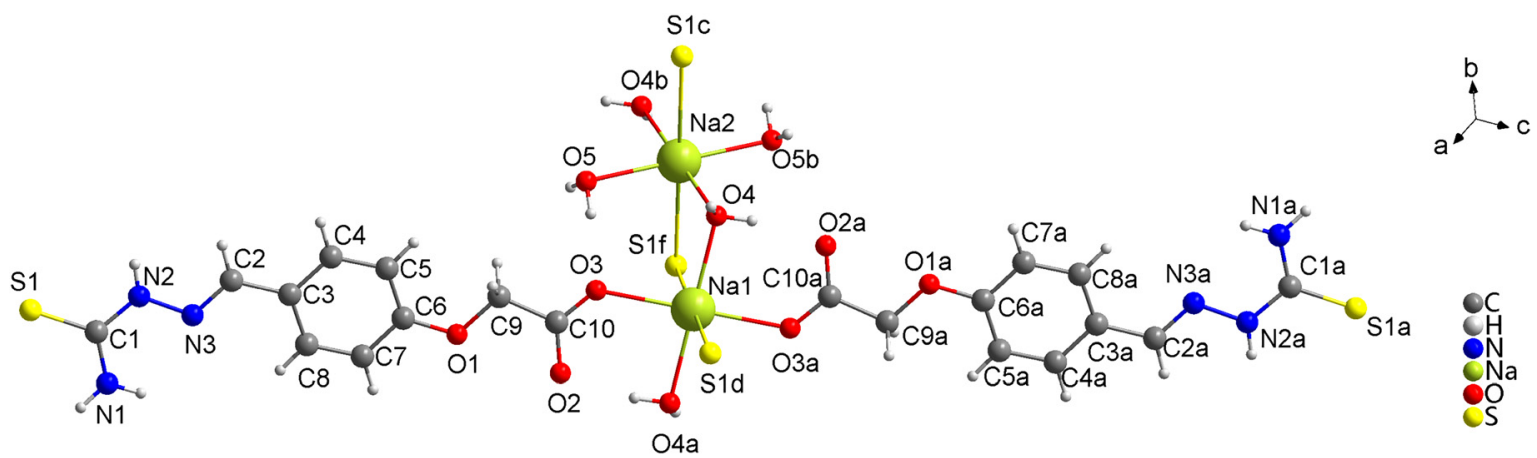

https://doi.org/10.1515/ncrs-2022-0006

Received January 9, 2022; accepted January 24, 2022;

published online February 15, 2022

\section{Abstract}

$\mathrm{C}_{10} \mathrm{H}_{14} \mathrm{~N}_{3} \mathrm{O}_{5} \mathrm{SNa}$, triclinic, $P \overline{1}$ (no. 2), $a=6.7015(5) \AA$, $b=7.5656(5) \AA, \quad c=14.1332(8) \AA, \quad \beta=93.159(5)^{\circ}$, $V=654.71(8) \AA^{3}, Z=2, R_{g t}(F)=0.0357, w R_{\text {ref }}\left(F^{2}\right)=0.0872$, $\mathrm{T}=273 \mathrm{~K}$.

\section{CCDC no.: 2082889}

The molecular structure is shown in the figure. Table 1 contains crystallographic data and Table 2 contains the list of the atoms including atomic coordinates and displacement parameters.

\section{Source of material}

4-Formylphenoxyacetic acid ( $0.5 \mathrm{mmol}, 0.0901 \mathrm{~g}$ ), thiosemicarbazide (0.5 mmol, $0.0456 \mathrm{~g})$ and $\mathrm{NaOH}(0.5 \mathrm{mmol}$,

\footnotetext{
*Corresponding author: Yu-Pei Xia, College of Chemistry and Chemical Engineering, Weifang University, Weifang, Shandong 261061, P. R. China, E-mail: yopoxia@126.com

Xi-Shi Tai and Li-Hua Wang, College of Chemistry and Chemical Engineering, Weifang University, Weifang, Shandong 261061, P. R. China. https://orcid.org/0000-0002-0050-1900 (X.-S. Tai)
}

Table 1: Data collection and handling.

\begin{tabular}{ll}
\hline Crystal: & Colorless block \\
Size: & $0.11 \times 0.10 \times 0.08 \mathrm{~mm}$ \\
Wavelength: & Mo $K \alpha$ radiation $(0.71073 \AA)$ \\
$\mu:$ & $0.30 \mathrm{~mm}^{-1}$ \\
Diffractometer, scan mode: & Rigaku SuperNova, $\omega$ \\
$\theta_{\text {max }}$, completeness: & $25.0^{\circ},>99 \%$ \\
$N(h k l)_{\text {measured }}, N(h k l)_{\text {unique }}, R_{\text {int }}:$ & $4268,2284,0.027$ \\
$C$ Criterion for $I_{\text {obs }}, N(h k l)_{\text {gt }}:$ & $I_{\text {obs }}>2 \sigma\left(I_{\text {obs }}\right), 1969$ \\
$N(\text { param })_{\text {refined }}:$ & 205 \\
Programs: & Bruker [1], Olex2 [2], \\
& SHELX [3], Diamond [4]
\end{tabular}

$0.020 \mathrm{~g}$ ) were dissolved into $20 \mathrm{~mL}$ of a $\mathrm{H}_{2} \mathrm{O}$ /ethanol solution (v:v $=1: 1$ ) with stirring at $50{ }^{\circ} \mathrm{C}$. After $20 \mathrm{~min}, \mathrm{MgCl}_{2} \cdot 6 \mathrm{H}_{2} \mathrm{O}$ $(0.5 \mathrm{mmol}, 0.1015 \mathrm{~g}$ ) was added to the mixture. The mixture was continued to react for $4 \mathrm{~h}$ at $80^{\circ} \mathrm{C}$ with stirring. The mixture was then cooled to room temperature and continued the stirring for $4 \mathrm{~h}$. Filtering the reaction mixture. After 20 days, the crystals of the title compound were obtained by slowing volatilization at room temperature. Elemental analysis (\%) calcd. for $\mathrm{C}_{10} \mathrm{H}_{14} \mathrm{~N}_{3} \mathrm{O}_{5} \mathrm{SNa}$ : C, 38.55; H, 4.50; N, 13.49. Found (\%): C, 38.66; H, 4.76; N, 13.17 .

\section{Experimental details}

The hydrogen atoms were positioned geometrically $(\mathrm{C}-\mathrm{H}=0.93-0.97 \AA$ and $\mathrm{N}-\mathrm{H}=0.86 \AA)$. Their $U_{\text {iso }}$ values were set to $1.2 U_{\text {eq }}$ of the parent atoms. 
Table 2: Fractional atomic coordinates and isotropic or equivalent isotropic displacement parameters $\left(\AA^{2}\right)$.

\begin{tabular}{lrrrr}
\hline Atom & $\boldsymbol{x}$ & $\boldsymbol{y}$ & $\boldsymbol{z}$ & $\boldsymbol{U}_{\text {iso* }} / \boldsymbol{U}_{\text {eq }}$ \\
\hline C1 & $1.2614(3)$ & $0.8211(3)$ & $0.20138(13)$ & $0.0093(4)$ \\
C2 & $0.8917(3)$ & $0.8458(3)$ & $0.36091(14)$ & $0.0105(4)$ \\
H2 & 0.829020 & 0.911663 & 0.325921 & $0.013^{*}$ \\
C3 & $0.8089(3)$ & $0.7887(3)$ & $0.45049(13)$ & $0.0096(4)$ \\
C4 & $0.6266(3)$ & $0.8194(3)$ & $0.47820(14)$ & $0.0105(4)$ \\
H4 & 0.560939 & 0.877113 & 0.439220 & $0.013^{*}$ \\
C5 & $0.5405(3)$ & $0.7665(3)$ & $0.56205(14)$ & $0.0105(4)$ \\
H5 & 0.417806 & 0.787286 & 0.578535 & $0.013^{*}$ \\
C6 & $0.6382(3)$ & $0.6822(3)$ & $0.62135(13)$ & $0.0098(4)$ \\
C7 & $0.8259(3)$ & $0.6554(3)$ & $0.59643(14)$ & $0.0114(5)$ \\
H7 & 0.894868 & 0.602880 & 0.636993 & $0.014^{*}$ \\
C8 & $0.9085(3)$ & $0.7064(3)$ & $0.51219(14)$ & $0.0113(5)$ \\
H8 & 1.031726 & 0.686224 & 0.495946 & $0.014^{*}$ \\
C9 & $0.3739(3)$ & $0.6464(3)$ & $0.73119(14)$ & $0.0103(4)$ \\
H9A & 0.259916 & 0.588714 & 0.678176 & $0.012^{*}$ \\
H9B & 0.403109 & 0.783253 & 0.744570 & $0.012^{*}$ \\
C10 & $0.2982(3)$ & $0.5538(3)$ & $0.81928(13)$ & $0.0099(5)$ \\
H2A & $1.047(4)$ & $0.929(3)$ & $0.2175(15)$ & $0.010(6)^{*}$ \\
H4A & $-0.330(4)$ & $0.620(3)$ & $0.9382(18)$ & $0.029(7)^{\star}$ \\
H4B & $-0.289(4)$ & $0.641(4)$ & $1.036(2)$ & $0.039(8)^{*}$ \\
H5A & $0.124(4)$ & $0.828(4)$ & $0.8493(18)$ & $0.039(8)^{*}$ \\
H5B & $0.259(4)$ & $1.004(3)$ & $0.8610(17)$ & $0.023(8)^{*}$ \\
N1 & $1.3532(3)$ & $0.7232(2)$ & $0.24710(11)$ & $0.0134(4)$ \\
H1A & 1.316859 & 0.694239 & 0.302336 & $0.016^{*}$ \\
H1B & 1.448956 & 0.688713 & 0.221483 & $0.016^{*}$ \\
N2 & $1.1127(3)$ & $0.8718(2)$ & $0.24420(12)$ & $0.0107(4)$ \\
N3 & $1.0488(3)$ & $0.8073(2)$ & $0.32929(11)$ & $0.0105(4)$ \\
Na1 & 0.000000 & 0.500000 & 1.000000 & $0.0124(3)$ \\
Na2 & 0.000000 & 1.000000 & 1.000000 & $0.0127(3)$ \\
O1 & $0.5654(2)$ & $0.62119(18)$ & $0.70468(9)$ & $0.0119(3)$ \\
O2 & $0.3924(2)$ & $0.45320(18)$ & $0.85119(9)$ & $0.0121(3)$ \\
O3 & $0.1427(2)$ & $0.58362(18)$ & $0.85230(9)$ & $0.0118(3)$ \\
O4 & $-0.2275(2)$ & $0.6722(2)$ & $0.98521(12)$ & $0.0132(3)$ \\
\hline & $0.1361(3)$ & $0.9456(2)$ & $0.85079(11)$ & $0.0141(4)$ \\
O5 & $1.33292(8)$ & $0.88919(7)$ & $0.09353(3)$ & $0.01171(17)$ \\
\hline
\end{tabular}

\section{Comment}

Metal coordination polymers show excellent properties in many areas of chemical engineering and materials [5-12]. According to the literature, the studies on synthesis and properties of metal coordination polymer mainly focuses on transition metals. In order to enrich the structure and properties of the metal coordination polymers, our research group is committed to studying the structure and properties of the alkaline earth metal coordination polymers [13-16]. At the same time, we have also studied the catalytic activity of some metal complexes [16]. In order to further investigate the structure and catalytic property of alkali earth metal coordination polymers, in this work, a new $\mathrm{Na}(\mathrm{I})$ coordination polymer has been synthesized by a one-pot method. The title coordination polymer was characterized by EA and single-crystal X-ray diffraction analysis.

As shown in Figure 1, the $\mathrm{Na}(\mathrm{I})$ coordination polymer it is made up of one $\mathrm{Na}(\mathrm{I})$ ions on inversion centers, one thiosemicarbazide ligand and two coordinated water molecules. Na1 and Na2 atoms adopt a six-coordinated octahedron configuration, where Na1 is coordinated with two $\mathrm{O}$ atoms and $\mathrm{S}$ atoms of two different $\mathrm{L}$ ligands and two $\mathrm{O}$ atoms of two water molecules, and $\mathrm{Na} 2$ is coordinated with four $\mathrm{O}$ atoms of four coordinated water molecules and $\mathrm{S}$ atoms of two different $\mathrm{L}$ ligands. Thus the title structure contains two different coordinated units: $\mathrm{Na}\left(\mathrm{O}_{\mathrm{L}}\right)_{2}\left(\mathrm{~S}_{\mathrm{L}}\right)_{2}$ $\left(\mathrm{O}_{\text {water }}\right)_{2}$ and $\mathrm{Na}\left(\mathrm{O}_{\text {water }}\right)_{4}\left(\mathrm{~S}_{\mathrm{L}}\right)_{2}$, which forms a chained structure by the $\mathrm{Na}-\mathrm{O}$ coordination which is further extended by the $\mathrm{Na}-\mathrm{S}$ coordination $\mathrm{S}$ atoms of $\mathrm{L}$ ligands. The Na (I) coordination polymer assembles an extended layered structure. All bond lengths and angles are in the expected ranges [17].

Author contributions: All the authors have accepted responsibility for the entire content of this submitted manuscript and approved submission.

Research funding: This project was supported by the National Natural Science Foundation of China (No. 21171132), the Natural Science Foundation of Shandong (ZR2014BL003), the Project of Shandong Province Higher Educational Science and Technology Program (J14LC01), Science Foundation of Weifang (2020ZJ1054), and Weifang University of Science and Technology (https://doi.org/10. 13039/501100010887).

Conflict of interest statement: The authors declare no conflicts of interest regarding this article.

\section{References}

1. Bruker. SAINT and SADABS; Bruker AXS Inc.: Madison, Wisconsin, USA, 2000.

2. Dolomanov O. V., Bourhis L. J., Gildea R. J., Howard J. A. K., Puschmann H. OLEX2: a complete structure solution, refinement and analysis program. J. Appl. Crystallogr. 2009, 42, 339-341.

3. Sheldrick G. M. Crystal structure refinement with SHELXL. Acta Crystallogr. 2015, C71, 3-8.

4. Brandenburg K. DIAMOND. Visual Crystal Structure Information System (ver. 3.2); Crystal Impact: Bonn, Germany, 2012.

5. Shun K., Ryota M., Shojiro K., Hiroshi N., Tetsuro K. Radical-based coordination polymers as a platform for magnetoluminescence. J. Am. Chem. Soc. 2021, 143, 5610-5615.

6. Yasuchika H., Natsumi S., Joe H., Yuichi K., Koji F. Thermosensitive Eu'll' coordination polymers with amorphous networks. ChemistrySelect 2021, 6, 2812-2816.

7. Wu M. X., Yang Y. W. A fluorescent pillarene coordination polymer. Polym. Chem. 2019, 10, 2980-2985. 
8. Fan W. W., Cheng Y., Zheng L. Y., Cao Q. E. Reversible phase transition of porous coordination polymers. Chem. Eur J. 2020, 26, 2766-2779.

9. Hu M. L., Abbasi-Azad M., Habibi B., Rouhani F., Moghanni-BavilOlyaei H., Liu K. G., Morsali A. Electrochemical applications of ferrocene-based coordination polymers. ChemPlusChem 2020, $85,2397-2418$.

10. Zhu W. J., Zhao J. Y., Chen Q., Liu Z. Nanoscale metal-organic frameworks and coordination polymers as theranostic platforms for cancer treatment. Coord. Chem. Rev. 2019, 398, 113009.

11. Tian F., Shen N., Huang K. L., Chen S. C., Chen Q., He M. Y. Construction of alkali-metal-based imidazolecarboxylate coordination polymers as efficient catalysts for solvent-free ringopening polymerization of caprolactone. Z. Anorg. Chem. 2021, 647, 704-713.

12. Wang L. H., Kong F. Y., Tai X. S. Crystal structure and catalytic activity of poly[bis(3-bromo-2-hydroxybenzaldehyde)2-aminopyrimidinemagnesium(II)] for hydrogenation of 1,3-butadiene. Bull. Chem. React. Eng. Catal. 2021, 16, 260-266.
13. Tai X. S., Zhao W. H. Synthesis, crystal structure, and antibacterial activity of magnesium(II) coordination polymers formed by hydrogen bonding. Res. Chem. Intermed. 2015, 41, 3471-3478.

14. Cao S. H., Tai X. S., Xin C. L. Synthesis, crystal structure and antitumor activity of a $\mathrm{Ca}$ (II) coordination polymer based on 4-acetylphenoxyacetate ligands. Chin. J. Struct. Chem. 2021, 40, 324-328.

15. Tai X. S., Wang X. Synthesis and crystal structure of a 1D chained coordination polymer constructed from $\mathrm{Ca}^{2+}$ and 2-[(E)(2-furoylhydrazono)methyl]benzenesulfonate. Crystals 2015, 5, 458-465.

16. Tai X. S., Wang X. Synthesis, structural characterization and antitumor activity of a $\mathrm{Ca}$ (II) coordination polymer based on 4-formyl-1,3-benzenedisulfonate-2-furoic acid hydrazide ligands. Crystallogr. Rep. 2017, 62, 242-245.

17. Naveen Tittal R. K., Ghule V. D., Kumar N., Kumar L., Lal K., Kumar A. Design, synthesis, biological activity, molecular docking and computational studies on novel 1,4-disubstituted-1,2,3-triazolethiosemicarbazone hybrid molecules. J. Mol. Struct. 2020, 1209, 127951. 